\title{
RESEARCH
}

\section{Changes in survival among elderly patients initiating dialysis from 1990 to 1999}

\author{
Sarbjit Vanita Jassal MB BCh MD, Lilyanna Trpeski MPH MD, Naisu Zhu MD, Stanley Fenton MD, \\ Brenda Hemmelgarn PhD MD
}

$\infty \quad$ See related article page 1055

\section{ABSTRACT}

Background: Over the past decade, there has been a steep rise in the number of people with complex medical problems who require dialysis. We sought to determine the life expectancy of elderly patients after starting dialysis and to identify changes in survival rates over time.

Methods: All patients aged $6_{5}$ years or older who began dialysis in Canada between 1990 and 1999 were identified from the Canadian Organ Replacement Register. We used Cox proportional hazards models to examine the effect that the period during which dialysis was initiated (era 1, 1990-1994; era 2, 1995-1999) had on patient survival, after adjusting for diabetes, sex and comorbidity. Patients were followed from initiation of dialysis until death, transplantation, loss to follow-up or study end (Dec. 31, 2004).

Results: A total of 14512 patients aged 65 years or older started dialysis between 1990 and 1999. The proportion of these patients who were 75 years or older at the start of dialysis increased from $32.7 \%$ in era 1 (1990-1994) to $40.0 \%$ in era 2 (1995-1999). Despite increased comorbidity over the 2 study periods, the unadjusted 1-, 3- and 5-year survival rates among patients aged $65-74$ years at dialysis initiation rose from $74.4 \%, 44.9 \%$ and $25.8 \%$ in era 1 to $78.1 \%, 51.5 \%$ and $33.5 \%$ in era 2 . The respective survival rates among those aged 75 or more at dialysis initiation increased from $67.2 \%$, $32.3 \%$ and $14.2 \%$ in era 1 to $69.0 \%, 36.7 \%$ and $20.3 \%$ in era 2. This survival advantage persisted after adjustment for diabetes, sex and comorbidity in both age groups $\left(6_{5}-74\right.$ years: hazard ratio [HR] $0.76,95 \%$ confidence interval $[\mathrm{Cl}] 0.72-$ $0.81 ; 75$ years or more: $\mathrm{HR} 0.86,95 \% \mathrm{Cl} 0.80-0.92$ ).

Interpretation: Survival after dialysis initiation among elderly patients has improved from 1990 to 1999 , despite an increasing burden of comorbidity. Physicians may find these data useful when discussing prognosis with elderly patients who are initiating dialysis.

Une version française de ce résumé est disponible à l'adresse www.cmaj.ca/cgi/content/full/I77/9/I033/DCI

CMAJ 2007;177(9):1033-8
W ithin general medical and subspecialty areas, chronic kidney disease is increasingly recognized as an important comorbid condition that is often associated with prolonged hospital stays and increased morbidity and mortality. ${ }^{1-3}$ As a result, internists and other specialists are more likely than before to be involved with the care of patients for whom dialysis needs to be started because of end-stage kidney disease. The majority of patients starting dialysis are 65 years or older at the time of their first treatment, and many are over 75 years. ${ }^{4}$ Given the heightened awareness of chronic kidney disease, its high prevalence, the association with multiple comorbidity, and the impact of dialysis on survival and quality of life, we sought to calculate the mean life expectancy of elderly patients who began dialysis at either $65-74$ years of age or at 75 years or more, and to identify whether there was any change in survival probability, or in the effect of comorbidity characteristics, on dialysis over the past decade.

\section{Methods}

\section{Data source}

Data for the period Jan. I, I990, to Dec. 3I, 2004, were obtained from the Canadian Organ Replacement Register. We identified all patients aged 65 years or more who began dialysis between Jan. I, I990, and Dec. 3I, 1994 (era I), and between Jan. I, I995, and Dec. 3I, 1999 (era 2). We extracted the following data: age, comorbidities, cause of primary renal disease at the time of dialysis initiation, dialysis modality used and patient outcome at study end (Dec. 3I, 2004). All of the patients whose data were included in the study had follow-up data available for a minimum of 5 years.

The Canadian Organ Replacement Register is a voluntary national registry maintained by the Canadian Institute for Health Information. Data at registration include demographic data (patient age, sex and race); the diagnosis of primary renal disease and details of comorbid conditions (e.g., the presence or absence of angina, previous myocar-

From the University Health Network (Jassal, Fenton) and the Canadian Institute of Health Information (Trpeski, Zhu), Toronto, Ont.; and the University of Calgary (Hemmelgarn), Calgary, Alta. 
dial infarction, pulmonary edema, diabetes mellitus [type I or type 2], previous cerebrovascular accidents, peripheral vascular disease, neoplasia, chronic obstructive lung disease, hypertension or other serious illness [defined as "a disease not falling into one of the previously-listed categories which is expected to greatly reduce 5 -year survival probability"]). (For the list of diagnoses of primary renal disease recorded in the Canadian Organ Replacement Register and the corresponding disease categories we used in our study, see online Appendix I [www.cmaj.ca/cgi /content/full/I77/9/1033/DC2].) Follow-up data are recorded annually and include data on changes in dialysis modality, death and causes of death. Data quality is maintained by means of continual cross-checking of data submitted in the different facility reports, ${ }^{5}$ with capture of $93 \%$ of all dialysis patients. ${ }^{6}$

We divided the data into 4 groups on the basis of patient age (65-74 years and 75 years or older) and period of dialysis initiation (era I, I990-I994; and era 2, I995-1999) for the purposes of comparison. Patients were followed from initiation of dialysis until death, transplantation, loss to follow-up or study end (Dec. 3I, 2004).

The study design was approved by the Canadian Organ Replacement Register through the formal assessment process of the Canadian Institute for Health Information.

\section{Statistical analysis}

We compared differences in patient characteristics for each of the 2 age groups and for each of the 2 study periods using analysis of variance with either Student's $t$ test or $\chi^{2}$ tests as appropriate. The change in survival over the 2 study periods was examined using Cox proportional hazards analysis. Two separate models, one for each of the 2 age groups, were created, with time to death as the dependent variable. Patients were censored at transplantation, loss to follow-up or study end (Dec. 3I, 2004). The effect of treatment era (era I, I9901994; and era 2, 1995-1999), for each of the 2 age groups, was determined after adjustment for the following comorbidities: cerebrovascular or peripheral vascular disease, diabetes mellitus, acute myocardial infarction or previous coronary artery bypass surgery, neoplasia, sex and initial dialysis modality (hemodialysis or peritoneal dialysis) (see online Appendix 2 for definitions used to determine the presence of these comorbidities, available at www.cmaj.ca/cgi/content/full/I77 /9/I033/DC2). To limit errors arising from underreporting, we combined cerebrovascular and peripheral vascular disease into one term "vascular disease" for analysis. Patients with either cerebrovascular or peripheral vascular disease or both were noted as having vascular disease. To account for regional differences in clinical practice, we included in the model the province in which treatment was received. We then

Table 1: Demographic characteristics of 14507 elderly patients* at initiation of dialysis, by age group and study period

\begin{tabular}{|c|c|c|c|c|c|c|}
\hline \multirow[b]{2}{*}{ Characteristic } & \multicolumn{3}{|c|}{ Age $65-74 \mathrm{yr}$ at dialysis initiation } & \multicolumn{3}{|c|}{ Age $\geq 75 \mathrm{yr}$ at dialysis initiation } \\
\hline & $\begin{array}{c}1990-1994 \\
n=3583\end{array}$ & $\begin{array}{l}1995-1999 \\
n=5513\end{array}$ & $p$ value & $\begin{array}{c}1990-1994 \\
n=1739\end{array}$ & $\begin{array}{c}1995-1999 \\
n=3672\end{array}$ & $p$ value \\
\hline Age, yr, mean (SD) & $69.6(2.8)$ & $69.6(2.8)$ & 0.81 & $79.1(3.6)$ & $79.3(3.6)$ & 0.42 \\
\hline Sex male, no. (\%) & $2100(58.6)$ & $3225(58.5)$ & 0.92 & $1016(58.4)$ & $2148(58.5)$ & 0.96 \\
\hline \multicolumn{7}{|l|}{ Primary renal disease, no. (\%) } \\
\hline Diabetes mellitus & $828(23.1)$ & $1654(30.0)$ & $<0.001$ & $238(13.7)$ & $628(17.1)$ & $<0.001$ \\
\hline Hypertensive or Ischemic disease & $957(26.7)$ & $1450(26.3)$ & 0.66 & $567(32.6)$ & $1311(35.7)$ & 0.02 \\
\hline Glomerulonephritis & 534 (14.9) & $639(11.6)$ & $<0.001$ & $223(12.8)$ & $378(10.3)$ & 0.006 \\
\hline Other & 677 (18.9) & $937(17.0)$ & 0.02 & $297(17.1)$ & $580(15.8)$ & 0.23 \\
\hline Unknown & $588(16.4)$ & $832(15.1)$ & 0.09 & $414(23.8)$ & $775(21.1)$ & 0.025 \\
\hline \multicolumn{7}{|l|}{ Comorbid condition, no. (\%) } \\
\hline Diabetes mellitus & $1082(30.2)$ & $2183(39.6)$ & $<0.001$ & $357(20.5)$ & 988 (26.9) & $<0.001$ \\
\hline Vascular disease $†$ & $824(23.0)$ & $1703(30.9)$ & $<0.001$ & $435(25.0)$ & $1091(29.7)$ & $<0.001$ \\
\hline Cardiac disease $\neq$ & $978(27.3)$ & $1742(31.6)$ & 0.001 & $400(23.0)$ & $1201(32.7)$ & $<0.001$ \\
\hline Neoplasia & $337 \quad(9.4)$ & $645(11.7)$ & $<0.001$ & $219(12.6)$ & $488(13.3)$ & 0.48 \\
\hline Other & $351 \quad(9.8)$ & $540 \quad(9.8)$ & 0.99 & $181(10.4)$ & $356 \quad(9.7)$ & 0.41 \\
\hline \multicolumn{7}{|l|}{ Initial treatment modality, no. (\%) } \\
\hline Peritoneal dialysis & $1233(34.4)$ & $1235(22.4)$ & $<0.001$ & $579(33.3)$ & $698(19.0)$ & $<0.001$ \\
\hline Hemodialysis in hospital & $2329(65.0)$ & $4245(77.0)$ & $<0.001$ & $1156(66.5)$ & $2952(80.4)$ & $<0.001$ \\
\hline $\begin{array}{l}\text { Home-based or self-care } \\
\text { hemodialysis }\end{array}$ & $21 \quad(0.6)$ & $33(0.6)$ & 0.94 & $3(0.2)$ & $22 \quad(0.6)$ & 0.045 \\
\hline
\end{tabular}

Note: SD = standard deviation

*The total number of patients included in the study was 14512 . This table presents the demographic characteristics of 14507 patients because only age and sex were known for 5 patients.

†Includes peripheral vascular disease and cerebrovascular disease.

flncludes myocardial infarction or previous coronary artery bypass graft surgery. 
used interaction terms between dialysis modality and study period (era) to determine whether the association between mortality and study period varied by dialysis modality.

We tested the proportional hazards assumption in all of the Cox models by examining plots of the log-negative log of the within-group survivorship function versus log-time, and by comparing Kaplan-Meier (observed) with Cox (expected) survival curves. Patients with missing comorbidity data were excluded. As a validation of this strategy to handle missing data, we included a separate analysis in which we assumed that patients with missing data had no comorbidity.

Life expectancy was estimated with the use of the life-table method and represents the number of expected years of life remaining if starting dialysis at different ages, during each of the 2 study periods. The use of data from the Canadian Organ Replacement Register for the calculation of life expectancy is criticized because it relies on data for a subset of patients who will not have been followed to the time of death. We used the method reported by Brown and colleagues ${ }^{7}$ to limit bias. With this method, right-sided censorship bias arising from individuals who were censored in the last year of follow-up is reduced by assuming that the survival probability remains stable over the following years. In our model, the life-years contributed by patients was estimated using this method until the survival in each study period (I year) fell below 0.0000 I years. All tests of significance were 2 -sided with a $p$ value $<0.05$.

\section{Results}

\section{Demographic characteristics}

A total of I $_{4} 5 \mathrm{I} 2$ patients aged 65 years or older initiated dialysis between Jan. I, I990, and Dec. 3I, I999. Their demographic characteristics, by study period, are listed in Table $\mathrm{I}$. The majority of patients $(62.7 \%)$ were aged $65-74$ years at the time of dialysis initiation, with the remaining $37.3 \%$ aged 75 years or more. Comorbidity data were missing in $5.9 \%$ of the cases.

The burden of comorbidity increased in both age groups over the 2 time periods (Table I). In particular, vasculopathy was common, with more than $53 \%$ of patients having at least one of cardiac, peripheral vascular or cerebrovascular disease.

For most of the patients, the initial treatment modality was hospital-based hemodialysis; $26.4 \%$ received home-based dialysis therapy (peritoneal dialysis, home-based hemodialysis or nocturnal home-based dialysis). The proportion of patients whose initial treatment was home based decreased over time in both age groups $(p=0.06)$. A total of $13.3 \%$ of patients switched dialysis modalities within the first 3 months of treatment, which resulted in a rate of persistence on initial dialysis modality at I year of $86.8 \%$ for hemodialysis and $62.0 \%$ for peritoneal dialysis. In total, $355(2.4 \%)$ of the patients underwent renal transplantation. The majority of these patients were aged $65-74$ years at the time of dialysis initiation (132 during 1990-1994 and 216 during 1995-1999).

\section{Life expectancy}

Estimates of life expectancy after dialysis initiation ranged from 2.I4 to 4.62 years depending on the patient's age at the start of dialysis (Table 2). Estimates were higher in era I (1995-I999) than in era 2 (1990-I994) in all age groups, with increases of about $17 \%-28 \%$. The absolute difference in life expectancy seen between the 2 study periods varied from 5.4 months (among patients aged 80 years or older at the start of dialysis) to II.3 months (among those aged 65-69 years at the start of dialysis). Death was most commonly attributed to cardiac or vascular events, although a substantial proportion of deaths were listed as being due to an unknown cause (data not shown).

\section{Era effect}

A comparison of the 2 study periods (era I, I990-I994; era 2, 1995-1999) showed a significant increase in the proportion of elderly patients who were 75 years or older at the start of dialysis (32.7\% [1740/5325] in era I v. 40.0\% [3672/9187] in era 2, $p<$ o.oI). In era I (I990-I994), the unadjusted I-, 3 - and 5-year survival rates were $77.9 \%, 50.2 \%$ and $30.9 \%$ among patients aged $65-74$ years and $68.8 \%, 35.7 \%$ and $18.7 \%$ among those aged 75 years or more. After adjustment for sex, comorbidity and initial dialysis modality, we found that the survival rates improved significantly over time in each of the 2 age groups (Figure I). Patients aged $65-74$ years experienced a $23 \%$ improvement in survival (hazard ratio [HR] $0.77,95 \%$ confidence interval [CI] $0.73^{-0.80}$ ), and those aged 75 or more experienced a $16 \%$ improvement (HR o.84, 95\% CI 0.79-0.89) (Figure 2 and Figure 3). The improvement in survival was similar among patients with diabetes as well as among those without diabetes (data not shown). No interaction between study period (era) and dialysis modality was found, which suggested that the improvement in survival over time did not vary by dialysis modality.

\section{Validation models}

Proportionality of hazards was confirmed in all of the Cox models. When we evaluated the validity of excluding patients with missing comorbidity data, the repeated analysis in which we assumed that all patients with missing comorbidity data had no comorbid disorders yielded similar results. Therefore, results of the analysis that excluded patients with missing comorbidity data are presented.

\section{Interpretation}

We used data from a large national registry to demonstrate that the estimated life expectancy of elderly patients starting dialysis improved significantly from I990 to I999. Our results

Table 2: Estimated life expectancy after dialysis initiation among 14512 elderly patients, by study period

Study period; estimated

\begin{tabular}{lcc}
\hline \multirow{2}{*}{$\begin{array}{l}\text { Age at onset } \\
\text { of dialysis, yr }\end{array}$} & \multicolumn{2}{c}{$\begin{array}{c}\text { Study period; estimated } \\
\text { life expectancy, mean }(95 \% \mathrm{Cl}), \mathrm{yr}\end{array}$} \\
\cline { 2 - 3 } & \multicolumn{1}{c}{$1990-1994$} & $1995-1999$ \\
\hline $65-69$ & $3.68(3.59-3.78)$ & $4.62(4.55-4.69)$ \\
$70-74$ & $3.09(3.00-3.18)$ & $3.92(3.85-3.98)$ \\
$75-79$ & $2.73(2.63-2.83)$ & $3.19(3.03-3.35)$ \\
$\geq 80$ & $2.14(2.03-2.25)$ & $2.59(2.51-2.67)$ \\
\hline
\end{tabular}

Note: $\mathrm{Cl}=$ confidence interval. 
suggest that this survival advantage persisted even after correction for higher comorbidity and case complexity. Among patients aged 65 years or more at the start of dialysis, life expectancy improved by 15\%-20\% from 1990-1994 to I9951999 (depending on patient age and comorbidity profile), well in excess of improvements seen among elderly people in the general Canadian population over the same period. ${ }^{8}$ These findings are important to physicians involved in the care of patients with complex comorbidity, because a significant number of these patients will have concurrent chronic medical conditions and may not always be considered as suitable candidates for dialysis. Physicians may find these data useful, together with quality-of-life data, when discussing prognosis with elderly patients initiating dialysis.

The most detailed report documenting the outcome of older patients receiving dialysis comes from the North Thames Dialysis Study, in which 22I patients were followed for 12 months. ${ }^{9}$ Survival at I year was similar to that seen in our study; however, further data are not available because of the limited follow-up. Other studies have shown shorter survival among older patients than among younger patients, even after correction for multiple comorbid conditions, ${ }^{10-14}$ although few compared survival over time for a specific age group, as we did. Our finding of improved survival over time is in contrast to that from a recent study in the United States involving patients aged 80 years or older at the start of dialysis. ${ }^{15}$ In their study, Kurella and colleagues ${ }^{15}$ were unable to find any difference in I-year survival between elderly patients initiating dialysis in 1996 and those initiating it in 2003. With a higher overall rate of dialysis initiation per million population in the United States than in Canada, it is possible that physicians in Canada are less likely than their American counterparts to offer dialysis to elderly patients whom they feel are unlikely to benefit, which may explain the survival advantage evident in our results.

It is beyond the scope of our study to determine why survival improved by such a degree. Official Canadian statistics suggest that life expectancy from birth has increased steadily by $2 \%-3 \%$ each decade and that, overall, survival among patients receiving dialysis has improved over time. ${ }^{8,16}$ It is unlikely that the substantial increase seen in our selected patient population, over a much shorter period, is attributable totally to a general increase in survival. Improved survival may be due in part to changes in dialysis therapy itself (e.g., newer dialysis membranes, technology and the use of erythropoietin), advances in other areas of medicine and newer medications available on the market. It is also tempting to speculate that the improved survival is attributable to the increased number of Canadian programs promoting awareness of chronic kidney disease, which lead to earlier detection, improved predialysis care and more timely initiation of dialysis. ${ }^{17-19}$

We found a decrease in the use of peritoneal dialysis among elderly patients over the study period. Although the use of home-based dialysis modalities may allow older, frail individuals to experience a better quality of life, there is concern that peritoneal dialysis has been associated with a survival disadvantage, particularly in older patients with diabetes..$^{20-22}$ Thus, the survival advantage seen in the second study period (1995-1999) may have been attributable to increased use of he- modialysis as the first dialysis modality. In our study, we found no difference in survival between patients who received peritoneal dialysis and those who received hemodialysis as the initial dialysis modality. We tested for a possible interrelationship (using an interaction term) between modality choice and study period and found no effect. Switching dialysis modalities appeared to be equally common in each of the 2 study periods, which suggests that the observed increase in survival was not attributable to the change in physician practices.

The data in our study demonstrated an increasing prevalence, over time, of diabetes and of cardiac, peripheral vascular and cerebrovascular disease in the study population. The increase in the prevalence of vascular disease is consistent with the observation that the prevalence of severely impaired glomerular filtration rate is higher among older, hypertensive patients than among their younger counterparts. ${ }^{23}$ Of interest, the observed prevalence of peripheral vascular disease was considerably lower in our study than that in the study by Lamping and colleagues in the North Thames Dialysis Study (data not shown), ${ }^{9}$ but similar to that reported by the United States Renal Data System. ${ }^{24}$ This discrepancy may be due in part to the use of different definitions or underreporting, particularly of peripheral vascular disease, in registry data. Although we acknowledge that underreporting is possible, the comorbidity profile for other diseases (e.g., myocardial infarction and neoplasia) was similar to that recorded by Lamping and colleagues and the United States Renal Data System., ${ }^{9,24}$

Despite the finding in our study that survival improved over time, the overall life expectancy of elderly patients initiating dialysis is short. Our data suggest that people starting dialysis at 65 years of age or more have a life expectancy of less than 5 years. Although the causes of death appear similar to those reported in other registries, we did not make further comparisons given the known limitations of registry data in the reporting of cause of death..$^{25-27}$

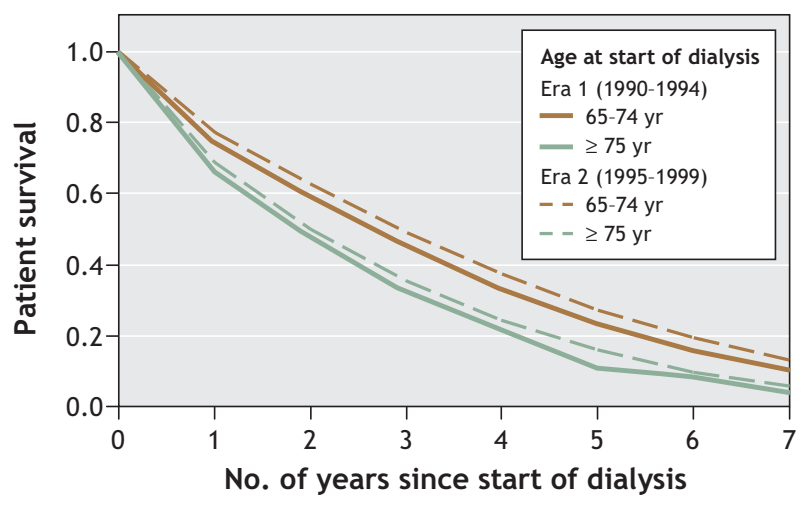

Figure 1: Survival curves for patients aged $65-74$ years and those aged 75 or more who began dialysis during 1990-1994 (era 1, solid lines) and 1995-1999 (era 2, dotted lines). Curves have been adjusted for sex; presence or absence of baseline cerebrovascular disease or peripheral vascular disease; previous myocardial infarction or coronary artery bypass surgery; diabetes at time of starting dialysis; neoplasia at time of starting dialysis; and initial dialysis modality. 
Our study, as with all studies that use administrative data sets, is limited by data quality. First, conditions such as liver disease, metastatic disease and concurrent respiratory disease are often overlooked by those abstracting data and may be underreported. However, it is unlikely that these data would be missing more frequently in one period than in another period. ${ }^{6}$ Also, we assessed the potential for bias due to missing data by including a validation model that assumed the "best case scenario" (that patients with missing comorbidity data did not have comorbid conditions) and found similar results. Second, although we have reported that both unadjusted and adjusted rates of death improved over time, we believe the adjustment for comorbidity to be of importance; however, the possibility of residual confounding cannot be excluded. Multiple authors have shown comorbidity to be a stronger predictor of outcome than age alone., ${ }^{78-30}$ We elected to adjust for individual comorbid conditions rather than use a collective score (e.g., the Charlson Comorbidity Index) to limit any bias arising from differences across scoring indices. Finally, information on changes in dialysis and medical care, which may affect changes in survival, were not available.

$\begin{array}{lc}\text { Variable } & \text { Hazard ratio }(95 \% \mathrm{C}) \\ \text { Era effect* }^{*} & 0.77(0.73-0.80) \\ \text { Diabetes mellitus* } & 1.27(1.21-1.34) \\ \text { Vascular disease* } & 1.25(1.19-1.32) \\ \begin{array}{l}\text { Myocardial infarction or } \\ \text { coronary artery bypass surgery* }\end{array} & 1.33(1.26-1.40) \\ \text { Neoplasia* } & 1.31(1.22-1.41) \\ \text { Sex } & 0.98(0.93-1.03) \\ \begin{array}{l}\text { Peritoneal dialysis } \\ \text { as first dialysis modality }\end{array} & 0.97(0.92-1.03)\end{array}$

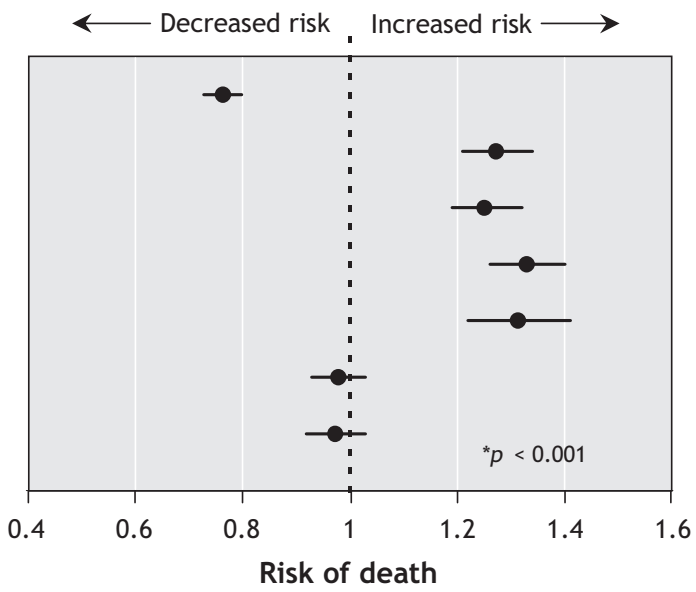

Figure 2: Adjusted risk of death following initiation of dialysis among patients aged $6_{5}-74$ years at the time of starting dialysis (based on 9076 of 9096 patients who had complete data). Point estimates show the estimated hazard ratio associated with each variable; the $95 \%$ confidence interval $(\mathrm{Cl})$ around the estimate is shown as a horizontal bar. The variable "era effect" is the hazard ratio for death between patients who began dialysis in era 2 (1995-1999) and those who began it in era 1 (1990-1994). Vascular disease is defined as the presence of either peripheral vascular disease or cerebrovascular disease, or both, at the time of dialysis initiation.

\begin{tabular}{|c|c|}
\hline Variable & Hazard ratio $(95 \%$ \\
\hline Era effect* & $0.84(0.79-0.89)$ \\
\hline Diabetes mellitus* & $1.09(1.02-1.17)$ \\
\hline Vascular disease* & $1.13(1.06-1.2$ \\
\hline $\begin{array}{l}\text { Myocardial infarction or } \\
\text { coronary artery bypass surgery* }\end{array}$ & $1.25(1.17-1.3$ \\
\hline Neoplasia† & $1.12(1.03-1.2$ \\
\hline Sex & $0.99(0.93-1.05)$ \\
\hline $\begin{array}{l}\text { Peritoneal dialysis } \\
\text { as first dialysis modality }\end{array}$ & $0.98(0.91-1.0$ \\
\hline
\end{tabular}

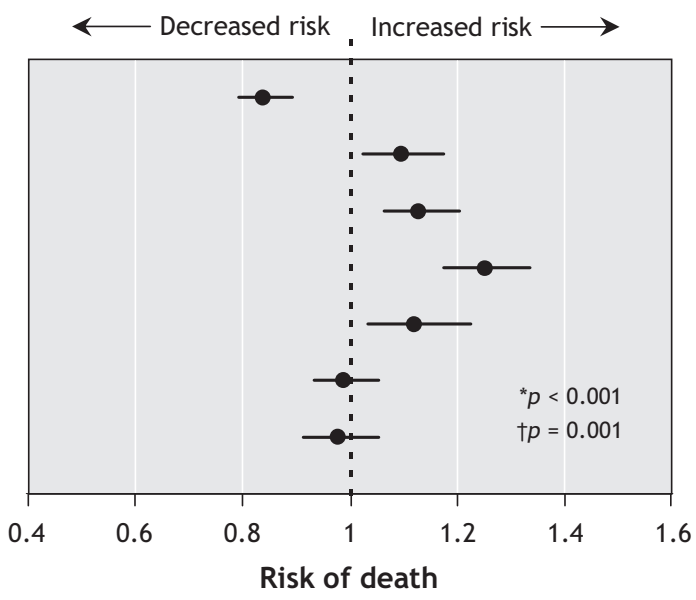

Figure 3: Adjusted risk of death following initiation of dialysis among patients aged 75 years or more at the time of starting dialysis (based on 5390 of 5411 patients who had complete data). Point estimates show the estimated hazard ratio associated with each variable; the $95 \%$ confidence interval $(\mathrm{Cl})$ around the estimate is shown as a horizontal bar. The variable "era effect" is the hazard ratio for death between patients who began dialysis in era 2 (1995-1999) and those who began it in era 1 (1990-1994). Vascular disease is defined as the presence of either peripheral vascular disease or cerebrovascular disease, or both, at the time of dialysis initiation. 
In conclusion, we found an increase in the number of elderly patients initiating dialysis from 1990 to 1999 . We also found a significant increase in the proportion of these patients who were 75 years or older. Despite an increase in their burden of comorbidity, elderly patients demonstrated improved survival over time. However, the overall life expectancy was limited. Age alone should not be used as a deterrent to initiating dialysis, but rather the decision should be made on an individual basis and other factors taken into account, including comorbidities, functional abilities and overall quality of life. Our study provides insight into only one aspect of dialysis care for elderly patients. When discussing prognosis, physicians should incorporate both an estimation of life expectancy and quality of life. Further studies are required to evaluate the economic impact of an increasing number of elderly dialysis patients who live longer.

\section{This article has been peer reviewed.}

Competing interests: None declared for Lilyanna Trpeski, Naisu Zhu, Stanley Fenton and Brenda Hemmelgarn. Vanita Jassal has held an investigator-driven grant from OrthoBiotec, has received speaker and consulting fees from Amgen Canada and OrthoBiotec, and has received speaker fees from Pfizer.

Contributors: Vanita Jassal was involved with the concept and design of the study, participated in the analysis and interpretation of the data and wrote and revised the manuscript. Lilyanna Trpeski and Naisu Zhu performed the data analysis and helped with the interpretation of the data and the writing and revision of the manuscript. Stan Fenton developed the initial concept of the study, participated in the interpretation of the data and helped with the revision of the manuscript. Brenda Hemmelgarn developed the concept and design methodology, participated in the analysis and interpretation of the data and was involved at all stages with the writing of the manuscript. All of the authors approved the final version of the manuscript for publication.

Acknowledgements: We thank Kim Badovinac at the Canadian Institute for Health Information for her help in starting this project and the initial analysis and interpretation of the data. The collection and maintenance of data in the Canadian Organ Replacement Register is made possible by the collaboration of the 87 renal programs across Canada. The contribution of the current and past full-time staff assigned to the registry at the Canadian Institute for Health Information (formerly the Hospital Medical Records Institute) has also been essential to the success of the registry. The Canadian Society of Nephrology, the Canadian Society of Transplantation, the Canadian Association of Nephrology Nurses and Technologists, the Canadian Association of Transplantation and their constituent members have also made an essential contribution to the registry since its inception in 198I. The Canadian Organ Replacement Register is wholly supported by grants from the federal, provincial and territorial ministries of health through the Canadian Institute for Health Information budget. The registry receives support from the Kidney Foundation of Canada for the printing of its annual reports.

This study was presented in part as a poster presentation at the American Society of Nephrology meeting held in Philadelphia, Nov. IO-I2, 2005.

\section{REFERENCES}

I. Hsu CY, Vittinghoff E, Lin F, et al. The incidence of end-stage renal disease is increasing faster than the prevalence of chronic renal insufficiency. Ann Intern Med 2004;I4I:95-IOI.

2. Muntner P, Coresh J, Powe NR, et al. The contribution of increased diabetes prevalence and improved myocardial infarction and stroke survival to the increase in treated end-stage renal disease. J Am Soc Nephrol 2003;I4:I568-77.
3. Mix TC, St Peter WL, Ebben J, et al. Hospitalization during advancing chronic kidney disease. Am J Kidney Dis 2003;42:972-8I.

4. Kidney Failure on the Rise, Seniors Constitute $50 \%$ of New Patients, reports Canadian Institute for Health Information. CIHI . 7-4-200I.

5. Canadian Institute for Health Information. Canadian Organ Replacement Register - data quality. Ottawa: The Institute. Available: http://secure.cihi.ca/cihiweb/dispPage.jsp?cw_page=services_corr_e\#quality (accessed 2007 july I8).

6. Canadian Institute for Health Information. Treatment of end-stage organ failure in Canada I995-2004 (2006 Annual Report). Ottawa: The Institute; 2006.

7. Brown JBW, Hollander M, Korwar RM. Nonparametric tests of independence for censored data with applications to heart transplant studies. In Proschan F, Serfling SJ, editors. Reliability and biometry: statistical analysis of lifelengths. Philadelphia: SIAM; I974. p. 327-54.

8. Population by sex and age group, by province and territory [table].Ottawa: Statistics Canada; 2003. Available: www.statcan.ca/english/Pgdb/demozra.htm (accessed 2007 July I8).

9. Lamping DL, Constantinovici N, Roderick P, et al. Clinical outcomes, quality of life, and costs in the North Thames Dialysis Study of elderly people on dialysis: a prospective cohort study. Lancet 2000;356:1543-50.

Io. Ismail N, Hakim RM, Oreopoulos DG, et al. Renal replacement therapies in the elderly: Part I. Hemodialysis and chronic peritoneal dialysis. Am J Kidney Dis I993;22:759-82.

II. Jassal SV, Douglas JF, Stout RW. Prognostic markers in older patients starting renal replacement therapy. Nephrol Dial Transplant I996;II:I052-7.

I2. Collins AJ, Weinhandl E, Snyder JJ, et al. Comparison and survival of hemodialysis and peritoneal dialysis in the elderly. Semin Dial 2002;15:98-102.

13. Krishnan M, Lok CE, Jassal SV. Epidemiology and demographic aspects of treated end-stage renal disease in the elderly. Semin Dial 2002;15:79-83.

I4. Ganesh SK, Hulbert-Shearon T, Port FK, et al. Mortality differences by dialysis modality among incident ESRD patients with and without coronary artery disease. J Am Soc Nephrol 2003;14:415-24.

I5. Kurella M, Covinsky KE, Collins AJ, et al. Octogenarians and nonagenarians starting dialysis in the United States. Ann Intern Med 2007;146:177-83.

I6. Canadian Organ Replacement Register. Dialysis and transplantation. Vol I. In: 2000 annual report. Ottawa: Canadian Institute for Health Information; 2000.

17. Ratcliffe PJ, Phillips RE, Oliver DO. Late referral for maintenance dialysis. $B M$ ) I984;288:44I-3.

I8. Jungers $P$, Zingraff J, Albouze $G$, et al. Late referral to maintainance dialysis: detrimental consequences. Nephrol Dial Transplant I993;8:1089-93.

I9. Kazmi WH, Obrador GT, Khan SS, et al. Late nephrology referral and mortality among patients with end-stage renal disease: a propensity score analysis. Nephrol Dial Transplant 2004;19:1808-I4.

20. Bloembergen WE, Port FK, Mauger EA, et al. A comparison of cause of death between patients treated with hemodialysis and peritoneal dialysis. J Am Soc Nephrol I995; 6:184-91.

2I. Collins AJ, Hao W, Xia H, et al. Mortality risks of peritoneal dialysis and hemodialysis. Am J Kidney Dis 1999;34:1065-74.

22. Vonesh EF, Snyder JJ, Foley RF, et al. Mortality studies comparing peritoneal dialysis and hemodialysis: what do they tell us? Kidney Int 2007;70:S3-II.

23. Rahman M, Brown CD, Coresh J, et al. The prevalence of reduced glomerular filtration rate in older hypertensive patients and its association with cardiovascular disease: a report from the Antihypertensive and Lipid-Lowering Treatment to Prevent Heart Attack Trial. Arch Intern Med 2004;164:969-76.

24. USRDS 2004 annual data report. Am J Kidney Dis 2005;45(Suppl I):8-28o.

25. Li SQ, Cass A, Cunningham J. Cause of death in patients with end-stage renal disease: assessing concordance of death certificates with registry reports. Aust N Z J Public Health 2003;27:419-24.

26. Perneger TV, Klag MJ, Whelton PK. Cause of death in patients with end-stage renal disease: death certificates vs registry reports. Am J Public Health 1993;83: I735-8.

27. Maitra S, Sekercioglu N, Baloch S, et al. Causes of death in older peritoneal dialysis patients: Can we depend on registry reports? Int Urol Nephrol 2007.

28. Fried L, Bernardini J, Piraino B. Charlson comorbidity index as a predictor of outcomes in incident peritoneal dialysis patients. Am J Kidney Dis 200I;37:337-42.

29. Hemmelgarn BR, Manns BJ, Quan H, et al. Adapting the Charlson comorbidity index for use in patients with ESRD. Am J Kidney Dis 2003;42:125-32.

30. Miskulin DC, Meyer KB, Martin AA, et al. Comorbidity and its change predict survival in incident dialysis patients. Am J Kidney Dis 2003;4I:I49-6I.

Correspondence to: Dr. Sarbjit Vanita Jassal, Rm. $8 \mathrm{~N}-857$, 200 Elizabeth St., Toronto ON M5G 2C4; fax $4{ }_{1} 63404999$; vanita.jassal@uhn.on.ca 